\title{
GERMINAÇÃO E PRODUÇÃO DE MUDAS DE TAMBORIL (Enterolobium contortisiliquum (VELL.) MORONG) EM DIFERENTES SUBSTRATOS ${ }^{1}$
}

\author{
Andréia Parra de Araújo² e Severino de Paiva Sobrinho ${ }^{3}$
}

\begin{abstract}
RESUMO - Tamboril (Enterolobium contortisiliquum (Vell.) Morong) é uma árvore de origem brasileira, que ocorre de norte a sul, pertencente à Família Leguminosea-Mimosoideae. O objetivo deste trabalho foi avaliar o efeito de diferentes substratos sobre a germinação e o crescimento dessa espécie. Os tratamentos utilizados foram: $\mathrm{T}_{1}$ - solo, $\mathrm{T}_{2}$ - solo + esterco bovino curtido, $\mathrm{T}_{3}-$ solo + palha de arroz carbonizada, e $\mathrm{T}_{4}-$ solo + esterco bovino curtido + palha de arroz carbonizada. As variáveis avaliadas foram: percentagem de emergência, índice de velocidade de emergência, altura da planta, número de folhas, diâmetro do caule, peso da matéria fresca e seca da parte área, e peso da matéria fresca e seca da raiz. O delineamento utilizado foi o inteiramente casualizado, com quatro tratamentos e cinco repetições de 20 sementes. A emergência e o índice de velocidade de emergência tiveram melhor desempenho nos substratos solo + esterco bovino curtido e solo + palha de arroz carbonizada. As características das mudas avaliadas, aos 120 dias após a semeadura, foram influenciadas positivamente pelo esterco bovino na composição do substrato.
\end{abstract}

Palavras-chave: Timbaúba, Crescimento de mudas e Emergência.

\section{GERMINATION AND PRODUCTION OF SEEDLINGS OF TAMBORIL (Enterolobium contortisiliquum (VELL.) MORONG) ON DIFFERENT SUBSTRATES}

\begin{abstract}
The Enterolobium contortisiliquum (Vell.) Morong. is a tree of Brazilian origin, occurring from north to south, from the family Leguminosea-Mimosoideae. The objective of this study was to evaluate the effect of different substrates on germination and seedling growth of tamboril. The treatments were: $T_{1}-$ soil, $T_{2}$ - soil + manure, $T 3$ - soil + carbonized rice straw and $T_{4}$ - soil + manure + carbonized rice straw. The evaluated variables included emergence percentage, emergence speed index, plant height, number of leaves, stem diameter, weight of the fresh and dry matter on the aerial parts and weight of fresh and dry root. The experimental design was completely randomized with four treatments and five replications of 20 seeds. The emergence and the emergence speed index had better performance in substrates soil + manure and soil + carbonized rice straw. The characteristics of the seedlings growh at 120 days after sowing has positively influenced by the presence of manure in the composition of the substrate.
\end{abstract}

Keywords: Timbaúba, Growth of seedlings and Emergency.

\section{INTRODUÇÃO}

Enterolobium contortisiliquum (vell.) Morong. é uma espécie pertencente à Família LeguminoseaMimosoideae, popularmente conhecida por tamboril, orelha-de-macaco, orelha-de-negro, tambori, timbaúba, timbó, tambaré, timbaúva, ximbó e pacará (LORENZI, 2002). É uma árvore de origem brasileira, ocorrendo no Pará, Maranhão e Piauí até o Mato Grosso do Sul e Rio Grande do Sul, nas florestas pluvial e semidecídua. É própria para a fabricação de barcos e de canoas de

\footnotetext{
${ }^{1}$ Recebido em 10.02.2009 e aceito para publicação em 18.04.2011.

${ }^{2}$ Graduação em andamento pela Universidade do Estado de Mato Grosso, UNEMAT, Brasil.

${ }^{3}$ Departamento de Agronomia, Universidade do Estado de Mato Grosso, UNEMAT, Brasil. E-mail: <paivasevero@unemat.br>.
} 
tronco inteiro, brinquedos, compensados, armações de móveis, miolo de portais, e caixotaria em geral, pois é de fácil manejo e acabamento (LORENZI, 2002). É uma planta decídua no inverno, de crescimento rápido, podendo chegar a mais de $4 \mathrm{~m}$ em dois anos, heliófita, seletiva higrófita, pioneira, dispersa em várias formações florestais. Na floresta primária é pouco comum e quase sempre concentrada em solos úmidos; é mais frequente em capoeiras com estágios mais adiantados da sucessão secundária (CORRÊA, 1984). É ótima para reflorestamento de áreas degradadas de preservação permanente em plantios mistos, principalmente por seu rápido crescimento inicial. Entretanto, pouco se sabe sobre a germinação e produção de mudas de Enterolobium contortisiliquum, o que em muitos casos leva ao insucesso daqueles que pretendem produzir mudas desta espécie.

Para que ocorra uma boa germinação de um determinado lote de sementes é necessário que as mesmas sejam colocadas em um substrato que lhe ofereça condições adequadas de luz, umidade, densidade e oxigênio. As condições que as sementes encontram nos solos nem sempre são adequadas para sua germinação. Fatores como estrutura, aeração, capacidade de retenção de água e grau de infestação de patógenos podem variar de um substrato para outro, interferindo no processo de germinação das mesmas (BARBOSA; BARBOSA, 1985).

Os substratos em geral têm como principal função dar sustentação às sementes, tanto do ponto de vista físico como químico e, são constituídos por três frações, a física, a química e a biológica. As frações físico-químicas são formadas por partículas minerais e orgânicas, contendo poros que podem ser ocupados por ar e/ou água e a fração biológica pela matéria orgânica (AGUIAR et al., 1993). Segundo Kampf (2000), as características físicas são importantes de serem observadas uma vez que podem influenciar no crescimento das mudas; por exemplo, quanto mais alta for à densidade do substrato, mais difícil se torna o cultivo no recipiente, podendo limitar o crescimento das mudas.

Na composição do substrato para o crescimento de plântulas, a fonte orgânica é responsável pela retenção de umidade e pelo fornecimento de parte dos nutrientes. Tradicionalmente, o esterco bovino é utilizado como fonte orgânica na composição de substratos para viveiros de mudas de café, de plantas hortícolas e de plantas arbóreas (FONSECA, 1988; SANTOS et al., 1994;
ANDRADE NETO et al., 1999). Para Cunha et al. (2006), a melhor "performance" das mudas de Acacia sp, comparando-se diferentes substratos com a mesma proporção de material orgânico, foi observada quando se utilizou esterco bovino.

No processo de produção de mudas é comum o uso de matéria orgânica misturada ao solo devido sua ação favorável sobre as propriedades físico-químicas do mesmo. A matéria orgânica, responsável pelo fornecimento de parte dos nutrientes às mudas e pela retenção de umidade, também influencia na densidade do substrato, na porosidade total e no espaço poroso do solo. Na realidade, a escolha por um determinado substrato vai depender da finalidade do uso, pois dificilmente se encontra um material com todas as características que atenda às condições para o ótimo crescimento e desenvolvimento das plantas (SOUZA et al., 1995). As características físicas, químicas e biológicas devem oferecer as melhores condições para que haja uma excelente germinação e favoreça o desenvolvimento de mudas (MINAMI; PUCHALA, 2000). O uso de um substrato inadequado pode ocasionar irregularidade ou até mesmo nulidade na germinação, logo, o substrato se constitui num dos fatores mais complexos na produção de mudas.

Com base no exposto, este trabalho teve por objetivo avaliar o efeito de diferentes substratos sobre a germinação (viabilidade e vigor) e verificar a influência do substrato no desenvolvimento (altura, diâmetro do caule, número de folhas, peso da matéria fresca da parte aérea e raiz e peso da matéria seca da parte aérea e raiz) de mudas de Enterolobium contortisiliquum.

\section{MATERIAL E MÉTODOS}

O ensaio foi realizado no Departamento de Agronomia da Universidade do Estado de Mato Grosso (UNEMAT). As sementes foram adquiridas no setor florestal do IFET Campus de Cáceres/MT. Em seguida, as sementes foram submetidas a tratamento pré-germinativo (escarificação com lixa) no Laboratório de Botânica da UNEMAT.

Para composição do substrato, foram utilizados solo (terra preta), esterco bovino curtido e casca de arroz carbonizada. Os substratos foram enviados para análise química no Laboratório de Solos da UNEMAT/ Pontes e Lacerda-MT. Os resultados estão apresentados na Tabela 1.

Revista Árvore, Viçosa-MG, v.35, n.3, Edição Especial, p. 581-588, 2011

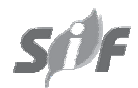


Tabela 1 - Dados da análise química dos substratos utilizados no estudo de emergência e desenvolvimento de mudas antes da semeadura.

Table 1 - Data on the chemical analysis of substrates used in the study of emergence and development of seedlings, before sowing.

\begin{tabular}{|c|c|c|c|c|c|}
\hline \multirow[t]{2}{*}{$\overline{\text { Elementos }}$} & \multirow[t]{2}{*}{ Unidade } & \multicolumn{4}{|c|}{ Substratos } \\
\hline & & $\mathrm{T}_{1}$ & $\mathrm{~T}_{2}$ & $\mathrm{~T}_{3}$ & $\mathrm{~T}_{4}$ \\
\hline$\overline{\mathrm{pH}}\left(\mathrm{CaCl}_{2}\right)$ & -- & 5,2 & 6,9 & 5,1 & 6,3 \\
\hline M. O. & dag.kg ${ }^{-1}$ & 2,2 & 4,4 & 4,6 & 6,6 \\
\hline Fósforo & mg.dm ${ }^{-3}$ & 2,1 & 113,5 & 18,1 & 91,7 \\
\hline Potássio & $\mathrm{cmol}_{\mathrm{c}} \cdot \mathrm{dm}^{-3}$ & 0,2 & 2,6 & 2,2 & 2,1 \\
\hline Cálcio & $\mathrm{cmol}_{\mathrm{c}}^{\mathrm{c}} \cdot \mathrm{dm}^{-3}$ & 5,8 & 7,3 & 4,8 & 7,5 \\
\hline Magnésio & $\mathrm{cmol}_{\mathrm{c}}^{\mathrm{c}} \cdot \mathrm{dm}^{-3}$ & 1,7 & 4,8 & 2,7 & 5,4 \\
\hline Alumínio & $\mathrm{cmol}_{\mathrm{c}}^{\mathrm{c}} \cdot \mathrm{dm}^{-3}$ & 0 & 0 & 0 & 0 \\
\hline $\mathrm{H}+\mathrm{Al}$ & $\mathrm{cmol}_{\mathrm{c}}^{\mathrm{c}} \cdot \mathrm{dm}^{-3}$ & 4,1 & 1,4 & 5,6 & 2,0 \\
\hline V & $\%$ & 65,6 & 91,2 & 63,3 & 88,5 \\
\hline
\end{tabular}
de base.

Os substratos utilizados foram: solo $-\mathrm{T}_{1}$; solo + esterco bovino curtido $(1: 1, \mathrm{v}: \mathrm{v})-\mathrm{T}_{2}$; solo + casca de arroz carbonizada $(1: 1, \mathrm{v}: \mathrm{v})-\mathrm{T}_{3}$; solo + esterco bovino curtido + casca de arroz carbonizada (1:1:1, $\mathrm{v}: \mathrm{v})-\mathrm{T}_{4}$. O solo utilizado foi um Argissolo Vermelho Amarelo Eutrófico.

Em cada tratamento (substrato) distribuído ao acaso foram semeadas 100 sementes de tamboril divididas em cinco repetições.Cada repetição foi constituída por 10 recipientes (sacos de polietileno preto com furos e dimensões de $29 \mathrm{~cm}$ x $9 \mathrm{~cm}$ ). Em cada recipiente, foram semeadas duas sementes a uma profundidade de $1,0 \mathrm{~cm}$ e irrigadas duas vezes ao dia durante os primeiros 30 dias, e o restante do período de formação das mudas uma vez ao dia. Aos 30 dias após a semeadura, foi realizado um desbaste (quando havia duas plantas por recipiente) e deixado apenas a planta mais vigorosa para avaliações posteriores. Avaliaram-se as seguintes características: (com exceção dos parâmetros de da emergência, as demais características foram avaliadas aos 120 dias após a semeadura).

- Emergência - foram utilizadas 100 sementes por tratamento, divididas em cinco repetições. A contagem do número de sementes germinadas teve início aos sete dias e se estendeu até os 24 dias após a semeadura. O critério utilizado foi o de plântulas normais que apresentavam as estruturas essenciais perfeitas (BRASIL, 1992).
- Índice de velocidade de emergência (IVE) - foram feitas contagens diariamente do $7^{\circ}$ até $24^{\circ}$ dia após a semeadura das plântulas normais, cujo índice foi calculado conforme equação proposta por Maguire (1962).

- Número de folhas por muda - foi feita uma contagem do número de folhas em cada muda de cada tratamento.

- Altura da planta - foi considerada altura da muda, a distância entre o colo da planta e a gema apical com uma régua milimétrica.

- Diâmetro do caule - com o auxílio de um paquímetro, foi medido o diâmetro do caule na região do colo da planta.

- Peso de matéria fresca da parte área e radicular - as mudas foram seccionadas na região do colo separando a parte aérea da parte radicular. Em seguida, foi acondicionada em sacos de papel e realizada a pesagem.

- Peso de matéria seca da parte aérea e radicular - após a pesagem da matéria fresca, o material foi desidratado em estufa regulada a $60^{\circ} \mathrm{C}$ por $72 \mathrm{~h}$, e, após este período, foi feita a pesagem.

Para avaliação do número de folhas por planta, altura da planta, diâmetro do caule, peso da matéria 
fresca e seca da parte aérea e raiz foram utilizadas 10 mudas por repetição, e a partir destes valores foi obtida à média de cada repetição.

O delineamento experimental utilizado foi o inteiramente ao acaso, consistindo de quatro tratamentos e cinco repetições. Os dados foram submetidos à análise de variância e as médias, comparadas pelo teste de Tukey, a 5\% de probabilidade. Os dados de percentagem de emergência foram transformados para arc. sen $(\mathrm{x} / 100)^{0,5}$

\section{RESULTADOS E DISCUSSÃO}

A emergência de sementes de Enterolobium contortisiliquum teve um percentual menor no substrato formado por solo e no substrato formado por solo + esterco bovino + casca de arroz carbonizada, e ambos os resultado foram inferiores aos apresentados pelos substratos: solo + esterco bovino e solo + casca de arroz carbonizada (Tabela 2).

Essa diferença entre os substratos pode ser atribuída à sua capacidade de manterem água nas proximidades das sementes, o que é desejável para obtenção da uniformidade de emergência e um bom estande (CARVALHO; NAKAGAWA, 2000). Isso explica porque o melhor desempenho obtido nos substratos solo + esterco bovino e solo + casca de arroz carbonizada, por apresentarem capacidade de retenção de água dentro da faixa adequada para emergência das sementes, o que contribuiu para maior uniformidade na oferta de água para as sementes no período de pré-emergência. Por outro lado, deve-se ressaltar que as interações entre os fatores que influenciam na emergência e germinação de sementes são importantes, visto que a capacidade de retenção de água e a quantidade de luz que o substrato permite chegar à semente podem ser responsáveis por diferentes respostas germinativas
(FIGLIOLA et al., 1993). Andrade e Pereira (1994) relatam que a capacidade de retenção de água de cada substrato, aliada às características intrínsecas que regulam o fluxo de água para as sementes, pode influenciar os resultados de germinação de sementes.

OIVE de sementes de tamboril foi menor nos substratos: solo e solo + esterco bovino + casca de arroz carbonizada (Tabela 2). O melhor desempenho do IVE obtido nos substratos: solo + esterco bovino e solo + casca de arroz carbonizada é uma conseqüência do percentual de emergência das sementes. O índice de velocidade de emergência pode ter sido influenciado pelo material que reteve a água na quantidade adequada. Esse comportamento sugere que os substratos em referência favoreçam a emergência das plântulas, possivelmente por apresentar menor impedimento físico à emergência. Vieira Neto (1998), observou que substratos compostos por palha de arroz e esterco, favoreceram o índice de velocidade de germinação em mudas de mangabeira.

Com relação ao número de folhas por planta e diâmetro do caule de mudas de tamboril, o substrato formado apenas por solo apresentou resultado inferior aos demais, entretanto não houve diferença entre os outros substratos utilizados (Tabela 3). Observando a Tabela 1, verifica-se que o substrato formado apenas por solo continha menor quantidade de matéria orgânica, uma baixíssima quantidade de fósforo e potássio em relação aos demais. Isso deve ter contribuído para o menor desempenho do número de folhas das mudas produzidas neste tratamento.

O número de folhas é um fator inteiramente ligado ao desenvolvimento da planta, visto que elas são o principal local onde ocorre à fotossíntese, e também por serem centros de reserva, fonte de auxina e cofatores de enraizamento que são translocados para a base, contribuindo, ainda, para a formação de novos tecidos,

Tabela 2 - Percentagem de emergência (aos 24 dias após a semeadura) e Índice de Velocidade de Emergência (dos 7 as 24 dias após a semeadura) de sementes de tamboril (Enterolobium contortisiliquum) em diferentes substratos.

Table 2 - Emergence percentage (of 24 days after sowing) and Emergence speed index (from 7 to 24 days after sowing) of seeds of tamboril (Enterolobium contortisiliquum) on different substrates.

\begin{tabular}{ccc}
\hline Substrato & Emergência (\%) & IVE \\
\hline $\mathrm{T}_{1}$ & $42,6 \mathrm{~B}$ & $0,448 \mathrm{~B}$ \\
$\mathrm{~T}_{2}$ & $77,4 \mathrm{~A}$ & $0,926 \mathrm{~A}$ \\
$\mathrm{~T}_{3}$ & $90,0 \mathrm{~A}$ & $0,996 \mathrm{~A}$ \\
$\mathrm{~T}_{4}^{4}$ & $53,4 \mathrm{~B}$ & $0,632 \mathrm{~B}$ \\
C.V.\% & 13,78 & 15,49 \\
\hline
\end{tabular}

solo+ casca de arroz carbonizada $\left(\mathrm{T}_{3}\right)$, solo + casca de arroz carbonizada + esterco bovino $\left(\mathrm{T}_{4}\right)$

Revista Árvore, Viçosa-MG, v.35, n.3, Edição Especial, p. 581-588, 2011 
Tabela 3 - Número de folhas, altura de mudas e diâmetro do caule de mudas de tamboril (Enterolobium contortisiliquum) em diferentes substratos, aos 120 dias de idade.

Table 3 - Number of leaves, height of seedlings and stem diameter of seedlings of tamboril (Enterolobium contortisiliquum) on different substrates, to give of age 120.

\begin{tabular}{lccc}
\hline Substrato & Número de folhas & Altura de mudas $(\mathrm{cm})$ & Diâmetro do caule $(\mathrm{mm})$ \\
\hline $\mathrm{T}_{1}$ & $6,08 \mathrm{~B}$ & $28,70 \mathrm{D}$ & $2,936 \mathrm{~B}$ \\
$\mathrm{~T}_{2}$ & $8,70 \mathrm{~A}$ & $90,26 \mathrm{~A}$ & $5,904 \mathrm{~A}$ \\
$\mathrm{~T}_{3}$ & $8,86 \mathrm{~A}$ & $43,00 \mathrm{C}$ & $5,356 \mathrm{~A}$ \\
$\mathrm{~T}_{4}$ & $8,50 \mathrm{~A}$ & $78,44 \mathrm{~B}$ & $5,338 \mathrm{~A}$ \\
$\mathrm{C} . \mathrm{V} \%$ & 13,40 & 9,85 & 20,37 \\
\hline
\end{tabular}

Médias seguidas pela mesma letra na coluna não diferem entre si, pelo teste de Tukey, a 5\%. Solo ( $\left.\mathrm{T}_{1}\right)$, solo + esterco bovino ( $\left.\mathrm{T}_{2}\right)$, solo+ casca de arroz carbonizada $\left(\mathrm{T}_{3}\right)$, solo + casca de arroz carbonizada + esterco bovino $\left(\mathrm{T}_{4}\right)$.

como as raízes, sendo por isso mais importante que os caules (PEREIRA et al., 1991; HARTMANN et al.,1997).

Trabalho realizado por Fernandez (2002) com mudas de Hancornia speciosa, por Arruda (2001) com Heteropteris aphrodisiaca e por Costa et al. (2002) com Genipa americana demonstraram que o número de folhas em mudas é influenciado pelo esterco bovino. Jesus (1997) observou que o número de folhas por planta era maior quando se utilizava substrato com matéria orgânica para produção de mudas de Piptadenia obliqua.

A presença de matéria orgânica nos substratos evidencia sua importância para a formação da mudas, uma vez que, quando formadas em substrato que continha um elevado teor de matéria orgânica, apresentaram maior diâmetro do caule.

Segundo Souza et al. (2006), o diâmetro do caule é um item fundamental para a avaliação do potencial de sobrevivência e crescimento no pós-plantio de mudas de espécies florestais. Segundo esses autores, dentro de uma mesma espécie, as plantas com maior diâmetro apresentam maior sobrevivência, por apresentarem capacidade de formação e de crescimento de novas raízes. O diâmetro do caule é um bom indicativo de qualidade de mudas e tem forte correlação com a porcentagem de sobrevivência de mudas (CARNEIRO, 1995).

A altura da muda de tamboril foi menor no substrato formado apenas por solo e máximo no tratamento solo + esterco bovino. As mudas do tratamento solo + casca de arroz carbonizada e solo + esterco bovino + casca de arroz apresentaram uma altura intermediária, e aquelas produzidas no tratamento solo + esterco bovino + casca de arroz foram maiores que as produzidas no tratamento solo + casca de arroz carbonizada (Tabela 3). Esses resultados ocorreram em função da presença do esterco nos substratos, pois sabe-se que o esterco tem uma rápida mineralização. Resultados semelhantes foram obtidos por Cunha et al. (2005) com mudas de Ipê-roxo (Tabebuia impetiginosa, Mart. Ex. D.C.), quando foi utilizado esterco bovino e de aves. Segundo Correia et al. (2001), o esterco é um componente orgânico que, com outros ,melhora as condições físicas do substrato, como aeração e drenagem, além de ser rico em nutrientes, que são rapidamente liberados para as plantas.

Para Gomes et al. (2002), a altura da planta apresenta uma boa contribuição para uma avaliação da qualidade de mudas, sendo essas características fáceis e viáveis de mensuração, além de não destruir as mudas.

Os substratos formados por solo + esterco bovino e solo + esterco bovino + casca de arroz carbonizada tiveram influência positiva no peso fresco da parte aérea das mudas, já o peso fresco da raiz das mudas nos substrato solo + esterco bovino, solo + casca de arroz carbonizada e solo + esterco bovino + casca de arroz carbonizada não diferiram entre si, mas o peso das raízes no substrato solo + esterco bovino + casca de arroz carbonizada foi superior ao peso das raízes das mudas do substrato solo (Tabela 4). Cunha et al. (2006), observaram que mudas de Acacia mangium e Acacia auriculiformes apresentaram menor desenvolvimento radicular quando o substrato não continha uma fonte orgânica. Para Dias et al. (2008), uma possível explicação para esse comportamento seria o fato de o adubo orgânico melhorar a estrutura do solo, permitindo o melhor desenvolvimento do sistema radicular. 
Tabela 4 - Peso fresco da parte aérea (P.F.A.), peso fresco da raiz (PFR), peso seco da parte aérea (PSA) e peso seco da raiz (PSR) da muda de tamboril em diferentes substratos, aos 120 dias de idade.

Table 4 -Fresh weight of the aerial parts, fresh weight of the root, dry weight of the aerial parts and dry weight of the root of the seedling of tamboril (Enterolobium contortisiliquum) on different substrates, to give of age 120.

\begin{tabular}{|c|c|c|c|c|}
\hline Substrato & PFA (g) & PFR (g) & PSA (g) & PSR (g) \\
\hline$\overline{\mathrm{T}_{1}}$ & $5,528 \mathrm{~B}$ & $5,150 \mathrm{~B}$ & $1,874 \mathrm{~B}$ & $1,212 \mathrm{~B}$ \\
\hline $\mathrm{T}_{2}$ & $23,034 \mathrm{~A}$ & $6,642 \mathrm{AB}$ & $6,286 \mathrm{~A}$ & $1,442 \mathrm{AB}$ \\
\hline $\mathrm{T}_{3}$ & $9,400 \mathrm{~B}$ & $8,734 \mathrm{AB}$ & $2,888 \mathrm{~B}$ & $1,980 \mathrm{AB}$ \\
\hline $\mathrm{T}_{4}$ & $18,922 \mathrm{~A}$ & $9,970 \mathrm{~A}$ & $6,062 \mathrm{~A}$ & $2,154 \mathrm{~A}$ \\
\hline C.V ${ }^{4} \%$ & 25,19 & 26,76 & 25,07 & 29,75 \\
\hline
\end{tabular}

Médias seguidas pela mesma letra na coluna não diferem entre si, pelo teste de Tukey ,a 5\%. Solo ( $\left.\mathrm{T}_{1}\right)$, solo + esterco bovino ( $\mathrm{T}_{2}$ ), solo+ casca de arroz carbonizada $\left(\mathrm{T}_{3}\right)$, solo + casca de arroz carbonizada + esterco bovino $\left(\mathrm{T}_{4}\right)$.

O efeito do esterco no incremento da massa verde também foi obtido por Cavalcanti et al. (2002), avaliando a fitomassa verde de plântulas de imbuzeiro em substrato composto com solo + esterco. Cunha et al. (2005) obtiveram resultados significativos no incremento de massa verde para mudas de Ipê- roxo (Tabebuia impetiginosa, Mart. Ex. D.C.) em substratos com esterco.

Cavalcanti et al. (2002), também observaram que o peso da raiz fresca de imbuzeiro foi maior quando se utilizou o tratamento solo + esterco. Clement e Machado (1997) afirmam que a incorporação de compostos orgânicos nos substratos pode influenciar o desenvolvimento da fitomassa e raízes de determinadas espécies florestais. Carvalho Filho et al. (2002) observou também que os melhores resultados para peso da raiz seca foi o substrato que continha esterco bovino.

O peso da parte aérea seca das mudas foi maior nos substratos formados por solo + esterco e solo +esterco bovino + casca de arroz carbonizada, já o peso da raiz seca apresentou diferença apenas entre o substrato solo e o substrato solo + esterco bovino + casca de arroz carbonizada, e no primeiro substrato os pesos foram menores (Tabela 4). No substrato solo, observou-se que as raízes apresentavam-se em menor número e desenvolvimento, tanto com relação ao número de raízes quanto tamanho e espessura. Silva et al. (2009), trabalhando com mangava, observaram que a adição de esterco ao substrato favorece a produção de peso das raízes secas.

Carvalho Filho et al. (2002) obtiveram os melhores resultados para peso da parte aérea seca, em substratos que continham em sua composição esterco bovino. Lima e Dornelles (2002) também observaram que a biomassa da parte aérea seca de plântulas de Anonna foi significativamente superior no substrato terra vegetal, em comparação com os demais substratos testados (vermiculita, areia lavada e serragem).

Observa-se que o peso da biomassa das mudas de tamboril é influenciado pela adição de uma fonte orgânica de nutriente porque esta fonte orgânica adicionada ao solo proporciona maior retenção de água, melhor a aeração das raízes e disponibiliza nutrientes para a muda.

\section{CONCLUSÃO}

A emergência e o vigor das sementes foram maiores nos tratamento solo + esterco bovino e solo + casca de arroz carbonizada. O desenvolvimento das mudas foi melhor nos tratamentos que continham esterco bovino (solo + esterco bovino e solo + esterco bovino + casca de arroz carbonizada).

\section{REFERÊNCIAS}

AGUIAR, I. B.; PIÑA-RODRIGUES, F. C. M.; FIGLIOLIA, M. B. Sementes florestais tropicais. Brasília: ABRATES, 1993. 350p.

ANDRADE NETO, A.; MENDES, A. N. G.; GUIMARÃES, P. T. G. Avaliação de substratos alternativos e tipo de adubação para a produção de mudas de cafeeiro em tubetes. Ciência e Agrotecnologia, v.23, n.2, p.270-280, 1999.

ANDRADE, A. C. S.; PEREIRA, T. S. Efeito do substrato e da temperatura na germinação e no vigor de sementes de cedro - Cedrela odorata L. (MELIACEAE). Revista Brasileira de Sementes, v.16, n.1, p.34-40, 1994. 
ARRUDA, J. B. Aspecto da germinação e cultivo do nó-de-cachorro (Heteropteris aphrodisiaca O. MACH.). 2001. 142f.

Dissertação (Mestrado em Agricultura Tropical) Faculdade de Agronomia e Medicina Veterinária, Universidade Federal de Mato Grosso, Cuiabá, 2001.

BARBosA, J. M.; BARBosA, L. M. Avaliação dos substratos, temperaturas de germinação e potencial de armazenamento de sementes de três frutíferas silvestres. Ecossistema, v. 10, p. 152-160, 1985.

BRASIL. Ministério da Agricultura e Reforma Agrária. Regras para análise de sementes. Brasília: SNDA/DNDV/CLAV, 1992. 365p.

\section{CARneiro, J. G. A. Produção e controle} de qualidade de mudas florestais. Curitiba: UFPR/FUPEF/Campos: UENF, 1995. 451p.

CARVALHO FILHO, J. L. SProdução de mudas de Cássia grandis L. em diferentes ambientes, recipientes e misturas de substratos. Revista Ceres, v.49, n.284, p.341-352, 2002.

CARVALHO, N. M.; NAKAGAWA, J. Sementes: ciência tecnologia e produção. 4.ed. Jaboticabal: FUNEP, 2000. 588p.

CAVALCANTI, N. B.; RESENDE, G. M.; BRITO, L. T. L. Emergência e crescimento do imbuzeiro (Spondias tuberosa Arr. Cam.) em diferentes substratos. Revista Ceres, v.49, n.282, p.97108, 2002.

CLEMENT, C. R.; MACHADO, F. M. Efeito da adubação orgânica na produção de biomassa em quebra-pedra (Phyllanthus stipulatus, Euphorbiaceae) em Manaus, Brasil. Acta Amazônica, v.27, n.2, p.73-80, 1997.

CORREIA, M. P. Dicionário das plantas úteis do Brasil e das exóticas cultivadas. Rio de Janeiro: Ministério da Agricultura/IBDF, 1984. 707p.

CORREIA, D.; CAVALCANTI JÚNIOR, A. T.; COSTA, A. M. G. Alternativas de substratos para a formação de portaenxertos de gravioleira (Annona muricata) em tubetes. Fortaleza: Embrapa Agroindústria Tropical, 2001. (Comunicado Técnico, 67).
COSTA, M. C. et al. Substratos para produção de mudas de jenipapo (Genipa americana L.). Pesquisa Agropecuária Tropical, v.35, n.1, p.19-24, 2005.

CUNHA, A. O. et al. Efeitos de substratos e das dimensões dos recipientes na qualidade das mudas de Tabebuia impetiginosa (Mart. Ex D.C.) Standl. Revista Árvore, v.29, n.4, p.507-516, 2005.

CUNHA, A. M. et al. Efeito de diferentes substratos sobre o desenvolvimento de mudas de Acacia sp. Revista Árvore, v.30, n.2, p.207-214, 2006.

DIAS, M. A. et al. Germinação de sementes e desenvolvimento de plantas de pimenta malagueta em função do substrato e da lâmina de água.

Revista Brasileira de Sementes, v.30, n.3, p.115-121, 2008.

FERNANDEZ, J. R. C. Efeito de substratos, recipientes e adubação na formação de mudas de mangabeira (Hancornia speciosa Gomes). 2002. 65f. Dissertação (Mestrado em Agricultura Tropical) - FAMEV/ UFMT, Cuiabá, 2002.

FIGLIOLA, M. B.; OLIVEIRA, E. C.; PIÑARODRIGUES, F. C. M. Análise de sementes. In: AGUIAR, I. R.; PIÑARODRIGUES, F. C. M.; FIGLIOLA, M. B. (Coords.). Sementes florestais tropicais. Brasília: ABRATES, 1993. p.137-174.

FONSECA, E. P. Efeito de diferentes substratos na produção de mudas de Eucalyptus grandis W. Hill ex Maiden em “Win-strip”. 1988. 81f. Dissertação (Mestrado em Ciência Florestal) - Universidade Federal de Viçosa, Viçosa, MG, 1988.

GOMES, J. M. et al. Parâmetros morfológicos na avaliação da qualidade de mudas de Eucalyptus grandis. Revista Árvore, v.26, n.4, p.515-523, 2002.

HARTMANN, H. T.; KESTER, D. E.; DAVIES JUNIOR, F. T. Plant propagation: principles and practices. 6.ed. New Jersey: Prentice Hall International, 1997. 770p. 
JESUS, B. M. Morfologia de sementes, germinação e desenvolvimento de mudas de angico-de-bezerro (Piptadenia obliqua (Pers.) Macbr.). 1997. 81f. Dissertação (Mestrado em Produção Vegetal) -Universidade Federal da Paraíba, Areia, 1997.

KAMPF, A. N. Produção comercial de plantas ornamentais. Guaíba: Agropecuária, 2000. 254p.

LIMA, A. L.; DORNELLES, A. L. C. Germinação de três espécies de Annona em diferentes substratos. In: CONGRESSO BRASILEIRO DE FRUTICULTURA, 18., 2002, Belém. Resumos... Belém: SBF/Embrapa Amazônia Oriental, 2002. CD ROM.

LORENZI, H. Árvores brasileiras: manual de identificação e cultivo de plantas arbóreas nativas do brasil. 4.ed. Nova Odessa: Instituto Plantarum, 2002. 384p.

MAGUIRE, J. D. Speed of germination-and in selection and evaluation for seeding emergence and vigor. Crop Science, v.2, n.2, p.176-177, 1962.

MINAMI, K.; PUCHALA, B. Produção de mudas de hortaliças de alta qualidade.

Horticultura Brasileira, v.18, p.162-163, 2000. Suplemento.
PEREIRA, F. M. et al. Efeito do ácido indolbutírico no enraizamento de estacas herbáceas de goiabeira (Psidium guajava L.) das cultivares 'Rica' e 'Paluma' em câmara de nebulização. Científica, v.19, p.199-206, 1991.

SANTOS, L. P.; CARVALHO, M. M.; CARVALHO, J. G. Efeitos de doses de nitrato de potássio e esterco de curral na composição do substrato para a formação de cafeeiro. Ciência e Prática, v.18, n.1, p.42-48, 1994.

SILVA, E. A. et al. Efeito de diferentes substratos na produção de mudas de mangabeira (Hancornia speciosa). Revista Brasileira de Fruticultura, v.31, n.3, p.925-929, 2009.

SOUZA, C. A. M. et al. Desenvolvimento em campo de espécies florestais em diferentes condições de adubação. Ciência Florestal, v.16, n.3, p.243-249, 2006.

SOUZA, M. M.; LOPES, L. C.; FONTES, L. E. F. Avaliação de substratos para o cultivo de crisântemo (Chrysanthemum morifolium Ramat., Compositae) 'White Polaris' em vasos. Revista Brasileira de Horticultura Ornamental, v.1, n.2, p.71-77, 1995.

VIEIRA NETO, R. D. Efeitos de diferentes substratos na formação de mudas de mangabeira (Hancornia speciosa Gomes). Revista Brasileira de Fruticultura, v.20, n.3, p.265-271, 1998. 